\title{
The Development of Hydroponic Nutrient Solutions Control Using Fuzzy and BPNN for Celery Plant
}

\author{
Arief Rahman $^{\text {a, }}$ Sri Wahjuni ${ }^{\text {a, }}$, Karlisa Priandana ${ }^{\text {a }}$ \\ ${ }^{a}$ Department of Computer Science, IPB University, Bogor, 16680, Indonesia \\ Corresponding author: *my_juni04@apps.ipb.ac.id
}

\begin{abstract}
As the increasing number of human populations, most live in urban areas with limited farmlands. Hydroponic is one of the solutions to grow crops in urban areas. Electrical Conductivity (EC) and scale of acidity (pH) in the hydroponic nutrient solution are the important things to be controlled. Controlling EC and $\mathrm{pH}$ in hydroponic can increase the quantity and quality of the crop. This research suggested a new method to merge fuzzy and Backpropagation Neural Network (BPNN) to control nutrient solutions in a Nutrient Film Technique hydroponic, with sensors EC and pH as input. The training data of BPPN are obtained from the implementation of the fuzzy technique. Controlling nutrient solutions can use fuzzy methods, but it has a weakness: use greater power because sensors require continuous detection. By using BPNN method, sensors only detect once to perform the same control action. In this research, the outputs of both methods are the duration of pumps in active conditions to optimize the nutrient solution. Based on experiments, the best BPNN model has eight hidden layers with a learning rate of 0.8 . The result accuracies which had been obtained

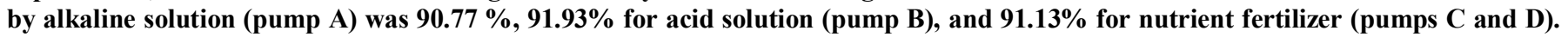
The result showed that the use of power for BPNN is less than fuzzy. The average total power used for BPNN method is $68.43 \%$ lower than the fuzzy method.
\end{abstract}

Keywords - Backpropagation; fuzzy; hydroponic; neural network; nutrient film technique.

Manuscript received 29 Nov. 2020; revised 17 Mar. 2021; accepted 28 Apr. 2021. Date of publication 28 Feb. 2022. IJASEIT is licensed under a Creative Commons Attribution-Share Alike 4.0 International License.

\section{INTRODUCTION}

According to the United Nations, the world's population could swell to 9.7 billion by 2050. In 2016, it was estimated that $54.5 \%$ of the world's population lived in urban areas. This number increases every year [1]. The increasing number of human populations living in urban areas affect people's lives, including the agricultural aspect [2]. People who live in the urban areas have limited farmlands [3]. One of the agricultural models that can be implemented in urban areas is hydroponic. The right water intake and nutrients are very important in the hydroponic system [4].

Nutrient Film Technique (NFT) is one of the hydroponic cultivation methods in which the root of the plant is circulated in a shallow water layer. It contains nutrition appropriate to the plants' needs [5]. Electrical Conductivity (EC) is a measurable amount of salts that dissolved or the fertilizer density in a hydroponic solution [6]. EC level is important for the plant [7]. It absorbs salts nutrition from the water [8]. Each plant in the hydroponic system has a different EC level [9]. The controlling of EC values can be done by fuzzy logic [10].
The controlling $\mathrm{pH}$ using fuzzy logic in addition by inputting $\mathrm{pH}$ for eel cultivation [11]. Backpropagation Neural Network (BPNN) algorithm can predict the amount of solution discharge needed by plant to keep EC and $\mathrm{pH}$ appropriate with the plant needs. BPNN has often been used to predict water distribution [12] and monthly rainfall prediction [13].

The research of Ponce et al. [8] controlled the output of solution in order to be appropriate with the plant needs with EC parameter. The use of fuzzy to set nutrition given to hydroponic plants using EC level was implemented in Ibrahim et al. [10]. According to research performed by Salintiro et al [17], $\mathrm{pH}$ in the hydroponic affected soil nutrients' solubility, resulting in better plant growth. Yolanda et al [1] could determine which nutrient solution would be given to maintain the value of $\mathrm{EC}$ and $\mathrm{pH}$ to meet the plant needs by using the fuzzy logic method. This Research by Yolanda et al. [1] had a weakness that the sensors must detect $\mathrm{EC}$ and $\mathrm{pH}$ continuously to instruct when the nutrient pump, acid pump solution and alkaline solution should be active or inactive.

Celery is one of the plants that the hydroponics system can plant. Celery (Apium graveolens L.) can be used as 
complementary cuisine or medicine [14]. The high demand of fresh celery has not been fulfilled in Indonesia [15]. Celery is a vegetable crop with many benefits and high economic value [16]. The research conducted is controlling the nutrient solution of the hydroponic system on celery plants with the BPNN decision-making method. Compared with the fuzzy method, this method has strength in not continuously detecting $\mathrm{EC}$ and $\mathrm{pH}$, so using the resources for $\mathrm{EC}$ and $\mathrm{pH}$ sensor becomes more efficient. BPNN that was implemented in Arduino can keep EC and pH under the plant needs.

\section{MATERIALS AND METHOD}

The research steps are depicted in Fig. 1. The Fuzzy method was used to collect data for BPNN training. Furthermore, experiments were conducted to compare the system's performance based on fuzzy inference and BPNN.

\section{A. Testing Environment}

This research built the hydroponic system with the container of nutrient solution only. There was 1 liter of solution that was controlled. This research uses four pumps, they are pump A for alkaline solution, pump B for acid solution, pump C and D for fertilizer solution. Pump A and B have $0.67 \mathrm{ml} / \mathrm{sec}$ speed of flowing solution, while pumps $\mathrm{C}$ and $\mathrm{D}$ have $0.48 \mathrm{ml} / \mathrm{sec}$ speed of flowing fertilizer solution. Alkaline Solution ( $\mathrm{pH}$ up) has $10 \%$ concentration of potassium hydroxide for increasing $\mathrm{pH}$ value. Acid solution ( $\mathrm{pH}$ down) has $10 \%$ concentration of phosphoric acid for reducing $\mathrm{pH}$ value. They are added with distilled water in ratio $1: 100$.

\section{B. Celery Plant Nutrition}

The nutrient solution concentration appropriate for the plants is needed to achieve the proper growth rate and get the maximum crop [10]. Nutrition is an important aspect of successfully planting in hydroponic [18]. In a hydroponic system, nutritional factors which affect are EC and $\mathrm{pH}$. Celery requires an $\mathrm{EC}$ value of $2.5-3$ and a $\mathrm{pH}$ value of 6 - 6.5 [19].

\section{Fuzzy Control Nutrient Solution}

This research used a fuzzy system that was adapted from [1], which are detailed as follows:

1. Inputs of fuzzy were $\mathrm{EC}$ sensor and $\mathrm{pH}$ sensor.

2. The membership functions for celery were:

a. The degree of membership values of $\mathrm{pH}$ acid ( $\mathrm{x}$ ) can be seen in Eq. (1) and Eq. (2):

$$
\begin{aligned}
& \mu p h a c i d \_H i g h[x]=\left\{\begin{array}{cc}
1 & x \leq 6 \\
\frac{6.5-x}{6.5-6} & 6 \leq x \leq 6.5 \\
0 & x \geq 6.5
\end{array}\right\} \\
& \mu \text { phAcid_Low }[x]=\left\{\begin{array}{cc}
1 & x \geq 6.5 \\
\frac{x-6}{6.5-6} & 6 \leq x \leq 6.5 \\
0 & x \leq 6
\end{array}\right\}
\end{aligned}
$$

where $x$ : observed value

b. The degree of membership values of $\mathrm{pH}$ alkaline (x) can be seen in Eq. (3) and Eq. (4):

$$
\text { uphAlkaline } \operatorname{High}[x]=
$$

$$
\left\{\begin{array}{cc}
1 & x \leq 6 \\
\frac{6.5-x}{6.5-6} & 6 \leq x \leq 6.5 \\
0 & x \geq 6.5
\end{array}\right\}
$$

$\mu$ phAlkaline_Low $[\mathrm{x}]=$

$$
\left\{\begin{array}{cc}
1 & x \geq 6.5 \\
\frac{6.5-x}{6.5-6} & 6 \leq x \leq 6.5 \\
0 & x \leq 6
\end{array}\right\}
$$

where $x$ : observed value

c. Value degree of memberhip, EC (x) can be seen in Eq. (5), Eq. (6) and Eq. (7):

$$
\begin{aligned}
& \mu E C_{-} L o w[x]=\left\{\begin{array}{cc}
1 & x \leq 1.5 \\
\frac{2.5-x}{2.5-1.5} & 1.5 \leq x \leq 2.5 \\
0 & x \geq 2.5
\end{array}\right\} \\
& \mu \operatorname{ex} O[x]= \\
& \left\{\begin{array}{cc}
0 & x \leq 1.5 \text { atau } x \geq 4 \\
(x-1.5) /(2.5-0.8) & 1.5 \leq x \leq 2.5 \\
1 & 2.5 \leq x \leq 3 \\
(4-x) /(4-3) & 3 \leq x \leq 4
\end{array}\right\} \\
& \mu E C_{-} H i g h[x]=\left\{\begin{array}{cc}
1 & x \leq 4 \\
\frac{x-3}{4-3} & 3 \leq x \leq 4 \\
0 & x \leq 3
\end{array}\right\}
\end{aligned}
$$

where $x$ : observed value

d. The degree of membership values of pump (z) can be seen in Eq. (8), Eq. (9), Eq. (10), and Eq. (11):

$$
\begin{array}{r}
\mu p H P u m p_{\text {On }[x]}= \\
\left\{\begin{array}{cc}
1 & x \leq 6 \\
\frac{6.5-x}{6.5-6} & 6 \leq x \leq 6.5 \\
0 & x \geq 6.5
\end{array}\right\} \\
\mu p H P u m p_{\text {Off }[x]}= \\
\left\{\begin{array}{cc}
1 & x \geq 6.5 \\
\frac{x-6}{6.5-6} & 6 \leq x \leq 6.5 \\
0 & x \leq 6
\end{array}\right\} \\
\mu E C P u m p_{\text {On }[x]}= \\
\left\{\begin{array}{cc}
1 & x \leq 2.5 \\
\frac{3-x}{3-2.5} & 2.5 \leq x \leq 3 \\
0 & x \geq 3
\end{array}\right\} \\
\mu E C P u m p_{\text {Off }[x]}= \\
\left\{\begin{array}{cc}
1 & x \geq 3 \\
\frac{x-2.5}{3-2.5} & 2.5 \leq x \leq 3 \\
0 & x \leq 2.5
\end{array}\right\}
\end{array}
$$

where $x$ : observed value.

3. The fuzzy rules to control hydroponic celery nutrient solution were:

a. The First Rules

Table $I$ is the rules defined to control the hydroponic nutrient solution for $\mathrm{pH}$ acid. For example, if EC is low and $\mathrm{pH}$ acid is high, pump $\mathrm{A}, \mathrm{C}$, and D are on.

b. The Second Rules

Table II is the rules defined to control hydroponic nutrient solution for $\mathrm{pH}$ alkaline. 

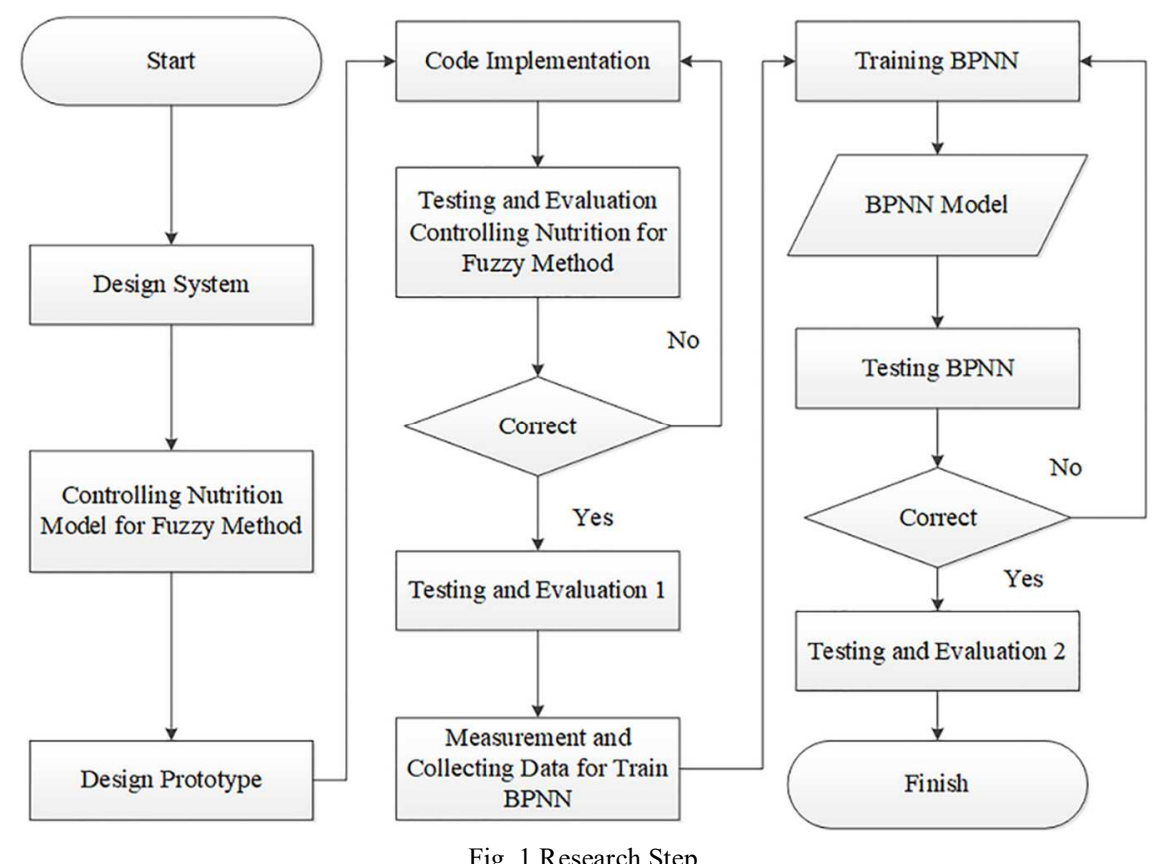

Fig. 1 Research Step

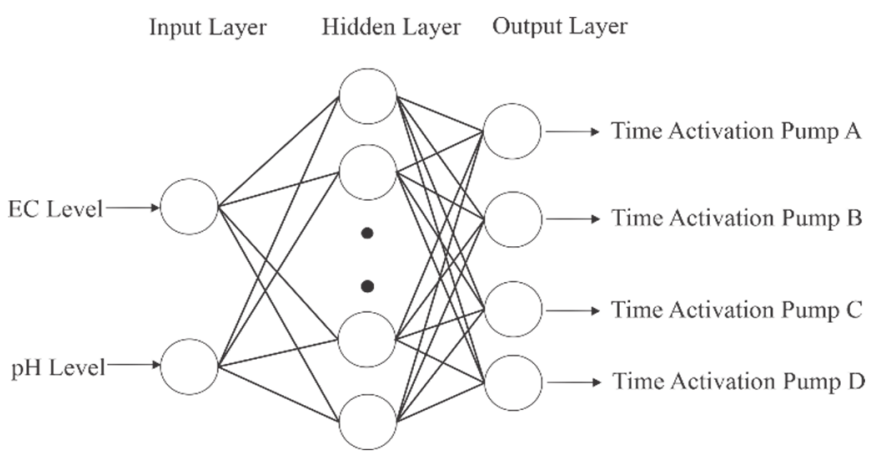

Fig. 2 The BPNN Model

TABLE I

THE FIRST RULES

\begin{tabular}{|c|c|c|}
\hline $\begin{array}{l}\text { IF- } \\
\text { THEN }\end{array}$ & pH Acid High & pH Acid Low \\
\hline EC Low & $\begin{array}{l}\text { Pump A ON AND Pump } \\
\text { C ON AND Pump D ON }\end{array}$ & $\begin{array}{l}\text { Pump A OFF AND Pump } \\
\text { C ON AND Pump D ON }\end{array}$ \\
\hline $\begin{array}{l}\text { EC } \\
\text { Optimal }\end{array}$ & $\begin{array}{l}\text { Pump A ON AND Pump } \\
\text { C OFF AND Pump D } \\
\text { OFF }\end{array}$ & $\begin{array}{l}\text { Pump A OFF AND Pump } \\
\text { C OFF AND Pump D OFF }\end{array}$ \\
\hline $\begin{array}{l}\text { EC } \\
\text { Tinggi }\end{array}$ & $\begin{array}{l}\text { Pump A ON AND Pump } \\
\text { C OFF AND Pump D } \\
\text { OFF }\end{array}$ & $\begin{array}{l}\text { Pump A OFF AND Pump } \\
\text { C OFF AND Pump D OFF }\end{array}$ \\
\hline \multicolumn{3}{|c|}{$\begin{array}{c}\text { TABLE II } \\
\text { THE SECOND RULES }\end{array}$} \\
\hline IF-THEN & pH Alkaline Low & pH Alkaline High \\
\hline EC Low & $\begin{array}{l}\text { Pump B OFF AND } \\
\text { Pump C ON AND Pump } \\
\text { D ON }\end{array}$ & $\begin{array}{l}\text { Pump B ON AND Pump C } \\
\text { ON AND Pump D ON }\end{array}$ \\
\hline $\begin{array}{l}\text { EC } \\
\text { Optimal }\end{array}$ & $\begin{array}{l}\text { Pump B OFF AND } \\
\text { Pump C OFF AND } \\
\text { Pump D OFF }\end{array}$ & $\begin{array}{l}\text { Pump B ON AND Pump C } \\
\text { OFF AND Pump D OFF }\end{array}$ \\
\hline EC High & $\begin{array}{l}\text { Pump B OFF AND } \\
\text { Pump C OFF AND } \\
\text { Pump D OFF }\end{array}$ & $\begin{array}{l}\text { Pump B ON AND Pump C } \\
\text { OFF AND Pump D OFF }\end{array}$ \\
\hline
\end{tabular}

4. The defuzzification to change fuzzy sets into reduction factor using the Eq. (12)

$$
Z=\frac{\sum_{i=1}^{n} \mu c \cdot z_{c}}{\sum_{i=1}^{n} \mu c}
$$

Where: $Z$ is the crisp output, $\mu c$ is the aggregated membership function, $z_{c}$ is the output variable, and $\mathrm{n}$ is number of observations.

\section{D. $B P N N$}

This research used the backpropagation method in its training, with a multilayer network consisting of three layers. The layers were input layer, hidden layer, and output layer. BPNN was used to build an automatic model which were expected to use smaller energy, because BPNN retrieved the data of nutrient solution only once. It was different from fuzzy that retrieved the data of nutrient solution continuously. The model of BPNN that was used in this research can be seen in the Fig. 2.

\section{RESULTS AND DISCUSSION}

This research used MATLAB Student R2018a for BPNN training. A PC ran it with processor Intel Core i5 of $2.6 \mathrm{GHz}$ speed and 8GB RAM.

\section{A. Fuzzy Evaluation}

This phase aimed to ensure whether or not EC sensor and $\mathrm{pH}$ sensor as fuzzy inputs and decision making of fuzzy methods were meet the predetermined rules. The experiments show that the fuzzy method results for controlling nutrient hydroponic solution provides the target range. Therefore, fuzzy method can be used for collecting data in neural network.

\section{B. Training and Validation Data for BPNN}

The implementation of the BPNN algorithm used training and testing data from the fuzzy method applied in section A. The output of BPNN is activation pump duration to reach levels of $\mathrm{EC}$ and $\mathrm{pH}$ that has been defined. The experiment was repeated three times with $\mathrm{EC}$ and $\mathrm{pH}$ in the same level. Table III shows some examples of training and validation data. Initial EC and Initial pH were obtained from the sensor, while Time Pump is the time activation pump resulting from the 
fuzzy method when producing optimal EC and $\mathrm{pH}$ (column Result EC and Result $\mathrm{pH}$ ) for celery plant. There were 106 data produced by the fuzzy method.

TABLE III

DATA SAMPLE OF TRAINING AND VALIDATION DATA

\begin{tabular}{|c|c|c|c|c|c|c|c|c|}
\hline \multirow{3}{*}{ No } & \multirow{3}{*}{$\begin{array}{l}\text { Initial } \\
\text { EC }\end{array}$} & \multirow{3}{*}{$\begin{array}{l}\text { Initial } \\
\text { pH }\end{array}$} & \multirow{2}{*}{\multicolumn{4}{|c|}{$\begin{array}{c}\text { Time Pump } \\
\text { (second) }\end{array}$}} & \multirow{3}{*}{$\begin{array}{l}\text { Result } \\
\text { EC }\end{array}$} & \multirow{3}{*}{$\begin{array}{l}\text { Result } \\
\text { pH }\end{array}$} \\
\hline & & & & & & & & \\
\hline & & & $\mathbf{A}$ & B & C & D & & \\
\hline 1 & 0.1 & 6.3 & 15 & 0 & 21.7 & 21.7 & 2.64 & 6.21 \\
\hline 2 & 0.16 & 6.9 & 60.4 & 0 & 21.4 & 21.4 & 3 & 6.21 \\
\hline 3 & 0.19 & 7 & 77 & 0 & 18 & 18 & 2.67 & 6.37 \\
\hline 4 & 0.2 & 6.85 & 0 & 26.3 & 15.2 & 15.2 & 2.58 & 6.46 \\
\hline 5 & 0.23 & 6.5 & 70 & 0 & 20.4 & 20.4 & 2.76 & 6.37 \\
\hline 6 & 0.4 & 4 & 79 & 0 & 14.7 & 14.7 & 2.73 & 6.5 \\
\hline 7 & 0.4 & 5.02 & 60.3 & 0 & 16.5 & 16.5 & 2.81 & 6.38 \\
\hline 8 & 0.4 & 6.05 & 48.2 & 0 & 15.3 & 15.3 & 2.96 & 6.23 \\
\hline 9 & 0.4 & 6.92 & 40.5 & 0 & 16.5 & 16.5 & 2.87 & 6.25 \\
\hline 10 & 0.4 & 7 & 0 & 0 & 16.5 & 16.5 & 2.74 & 6.22 \\
\hline
\end{tabular}

\section{Data Normalization}

Data normalization was needed because several variables had different values. Normalization in this research served to transform data into range 0 - 1 . It can be calculated by using Eq. (15). The fuzzy normalized data that were used for training and validation in BPNN are shown in Table IV.

TABLE IV

THE RESULTS OF NORMALIZATION DATA

\begin{tabular}{lllllll}
\hline No & $\begin{array}{l}\text { Initial } \\
\text { EC }\end{array}$ & Initial & \multicolumn{4}{c}{$\begin{array}{c}\text { Time } \\
\text { Pump }\end{array}$} \\
& & & A & B & C & D \\
\hline 1 & 0 & 0.3402 & 0.0652 & 0 & 1 & 1 \\
2 & 0.0207 & 0.4021 & 0.2626 & 0 & 0.9862 & 0.9862 \\
3 & 0.0310 & 0.4124 & 0.3348 & 0 & 0.8295 & 0.8295 \\
4 & 0.0345 & 0.3969 & 0 & 0.1638 & 0.7005 & 0.7005 \\
5 & 0.0448 & 0.3608 & 0.3043 & 0 & 0.9401 & 0.9401 \\
6 & 0.1034 & 0.1031 & 0.3435 & 0 & 0.6774 & 0.6774 \\
7 & 0.1034 & 0.2082 & 0.2622 & 0 & 0.7604 & 0.7604 \\
8 & 0.1034 & 0.3144 & 0.2096 & 0 & 0.7051 & 0.7051 \\
9 & 0.1034 & 0.4041 & 0.1761 & 0 & 0.7604 & 0.7604 \\
10 & 0.1034 & 0.4124 & 0.0000 & 0 & 0.7604 & 0.7604 \\
\hline
\end{tabular}

$$
\operatorname{Normal}\left(X_{i}\right)=\frac{\left(X_{i}-\operatorname{Min}(X)\right)}{(\operatorname{Max}(X)-\operatorname{Min}(x))}
$$

Where: $\operatorname{Min}(\mathrm{x})$ is $\min$ value from data list, $\operatorname{Max}(\mathrm{x})$ is $\max$ value from data list. $X_{i}$ is observed value.

\section{BPNN Training}

The data in this research were divided by $80 \%$ for training and $20 \%$ for validation. This research used BPNN model with 1 hidden layer with eight neurons and 5000 iterations with the learning rate of 0.8 . This best model was obtained from the model that had the smallest MSE value. The training was performed using Matlab Student R2018a with the traingd as the training network function. The transfer functions used are logsig and tansig. C and D pumps were put together in the training phase because both pumps must have the same activation time.

\section{E. The Results of Training}

The best validation performance result obtained at the numbers of epoch 1718, which produced the smallest Mean Squared Error (MSE) at $47418 \times 10^{-3}$. The level of errors in BPNN algorithm usually is measured using Root Mean Square Error (RMSE). The lower the error level, the better methodology that was used. Another parameter that can be used to measure the performance is Mean Absolute Percentage Error (MAPE), which is the percentage of error actual value and predictive value [20]. It is also used to measure the value of deviation from the actual value and predictive value. The RMSE and MAPE are calculated using Eq. (13) and Eq. (14), and results are shown in Fig. 3.

$$
\begin{aligned}
R M S E & =\sqrt{\frac{\sum_{j=1}^{n}\left(\hat{\mathrm{y}}_{i}-\boldsymbol{y}_{i}\right)^{2}}{n}} \\
\boldsymbol{M A P E} & =\frac{1}{n} \sum_{j=1}^{n}\left|\frac{\boldsymbol{y}_{i}-\hat{\mathrm{y}}_{i}}{\boldsymbol{y}_{\boldsymbol{i}}}\right|
\end{aligned}
$$

Where: $\hat{y}_{\boldsymbol{i}}$ predicted value, $y_{i}$ observed value, and n number of observations.

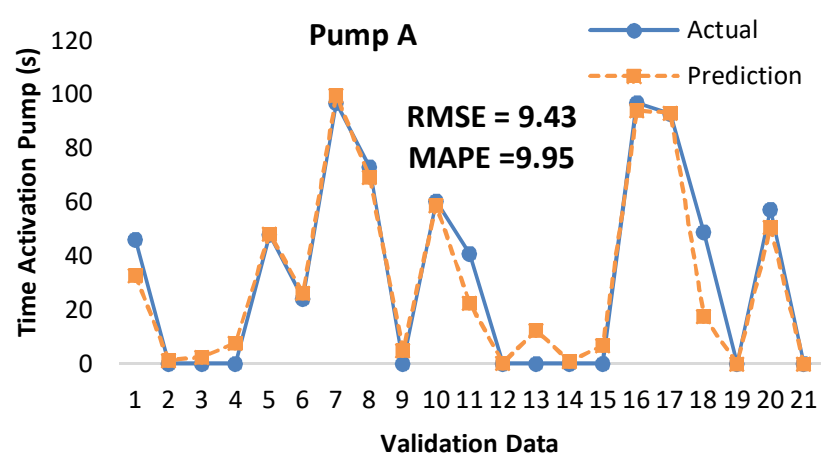

(a) Time activation of alkaline solution's pump

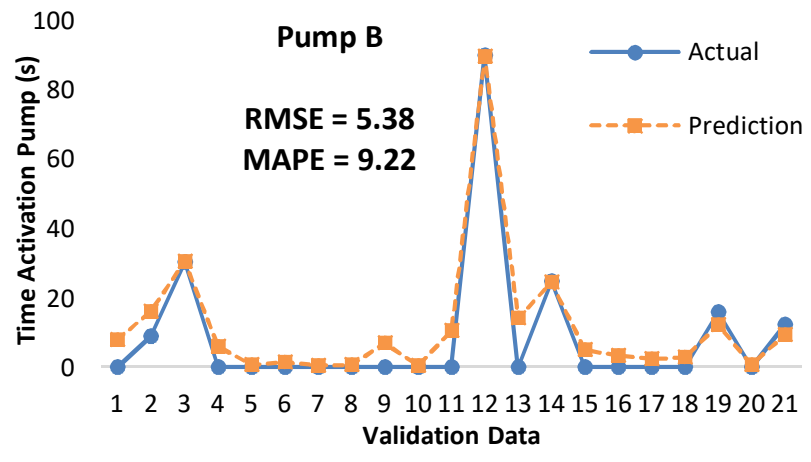

(b) Time activation of acid solution's pump

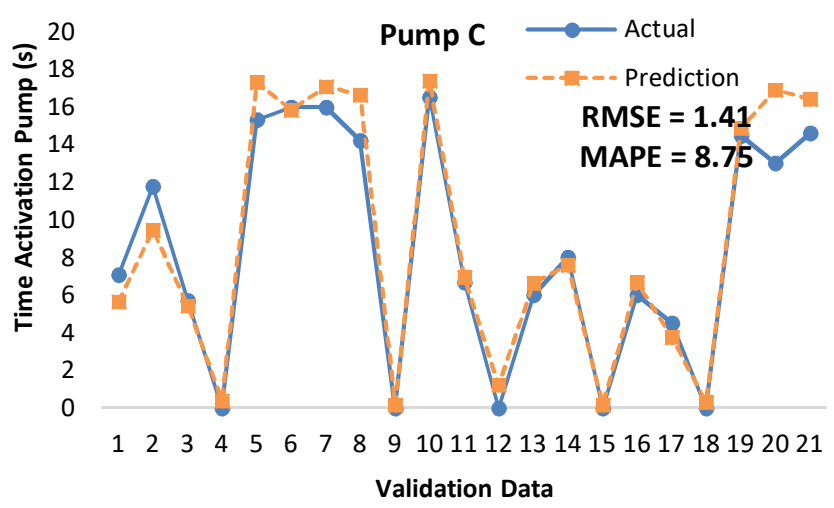

(c) Time activation of EC solution's pump

Fig. 3 The result of training

Once the prediction results are known, the accuracy level of data obtained from the model can be calculated. The fix model obtained validates data which already been segregated. We can see in Fig. 3 (a) and Fig. 3(b) that the pump A and B controlling nutrient solution for $\mathrm{pH}$ produce identical actual 
and prediction values. A similar pattern result also obtained from pump $\mathrm{C}$ that controls the $\mathrm{EC}$, as shown in Fig. 3(c).

\section{F. The Comparison of Accuracy and Power Use}

This step compares the accuracy and power usage of the fuzzy and BPNN methods. Both methods were compared using the same nutrient solution and same target range for celery plants by doing eight testing. The accuracy comparison was made by plotting the $\mathrm{pH}$ and $\mathrm{EC}$ value produced by both methods, and the minimum and maximum values should be referred to. The comparison was made for the power usage by measuring battery tension and current used before and after testing and then calculating the wattage.

Fig. 4(a) shows that the BPPN method outperforms the fuzzy method by producing more consistent $\mathrm{pH}$ values in the specified range (6.0-6.5). In Fig. 4(b), we can see that the BPNN method could adjust EC according to plant needs (2.53 ). In the experiment using the fuzzy method, the pump stopped when it reached the value in the specified range. But, its value kept growing up/down and sometimes had a higher/lower value than the plant desired. It happens because the sensor continuously collects data while mixing evenly of the nutrient solution spend more time. That causes the accuracy result for the fuzzy method to be worse than the BPNN method for those measurements.

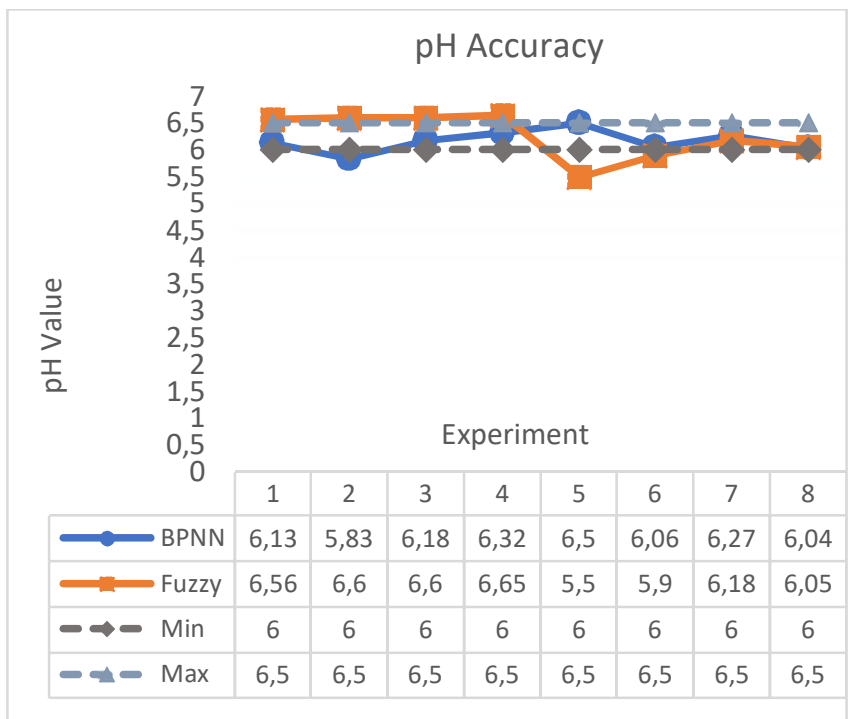

(a) The comparison of $\mathrm{pH}$ accuracy

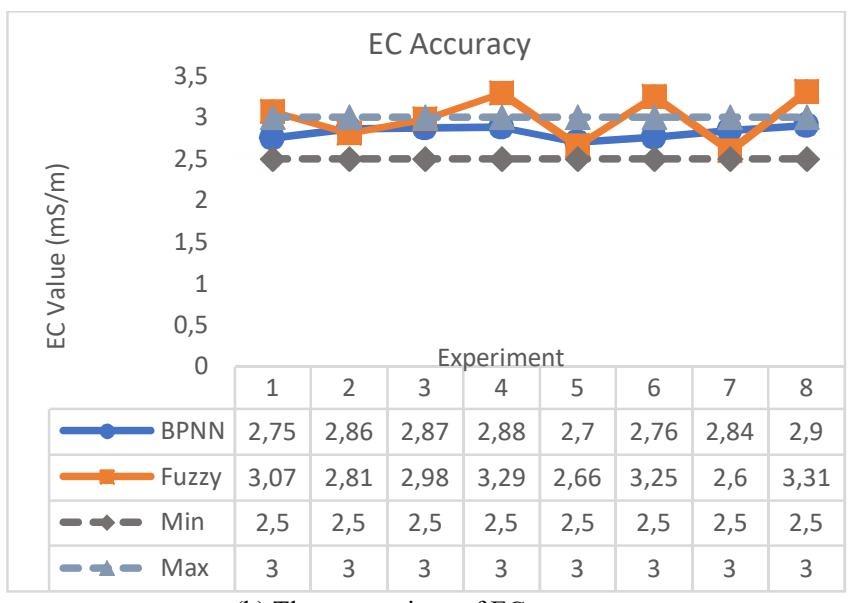

(b) The comparison of EC accuracy

Fig. 4 The comparison of $\mathrm{pH}$ and EC accuracy
The comparison of power usage measurement results can be seen in Fig. 5. The use of power for the BPNN method was smaller than that of the fuzzy method since the BPNN method only needs to read the sensor once for optimizing the nutrient solution that plants need. It was contradictive with the fuzzy method that doing sensing over time until the assigned value was achieved. Consequently, implementing a fuzzy method requires greater power than that of BPNN.

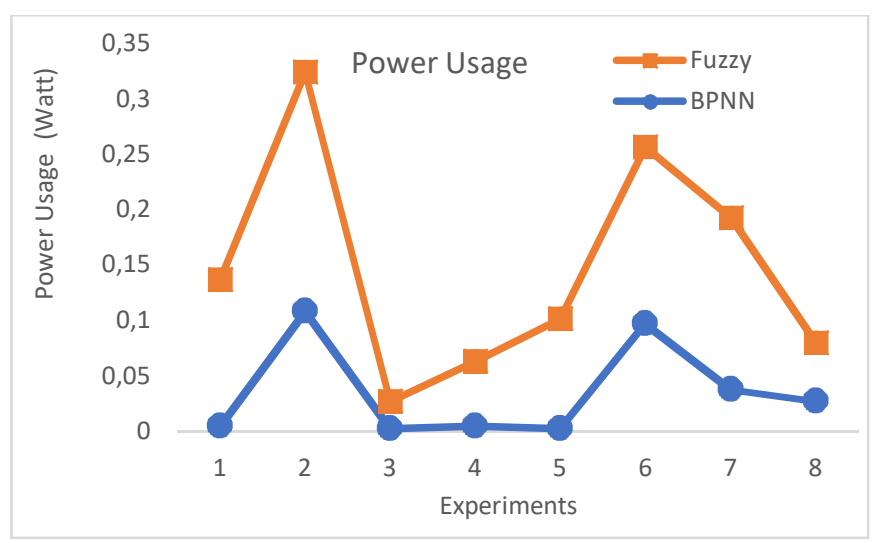

Fig. 5 The comparison of power usage

\section{CONCLUSION}

Experiments results in this research showed that the fuzzy and BPNN could be implemented to control the hydroponic nutrient solution of the celery plant. The fuzzy method had lower accuracy and higher power consumption levels than the BPNN method, which had higher accuracy and lower power consumption. The fuzzy method produces worse accuracy because although the pumps stopped when they achieved the assigned value, the value kept growing up/down out of the specified range. The sensor continuously collected data until the assigned value was reached, which caused extensive power consumption. On the contrary, the BPNN method only needs to collect data once, taking lower power usage. By using data from the learning method in BPNN makes its accuracy better. The BPNN method produces $68,53 \%$ less energy consumption than the fuzzy method.

\section{REFERENCES}

[1] D. Yolanda, H. Hindersah, F. Hadiatna, and M.A Triawan, "Implementation of Real-Time Fuzzy Logic Control for NFT-Based Hydroponic System on Internet of Things Environment", International Conference on System Engineering and Technology (ICEST., vol. 6, pp. 153-159, 2016.

[2] Y. L. Su, Y. F Wang, and D. W. Ow, "Increasing Effectiveness of Urban Rooftop Farming Through Reflector-assisted Double-layer Hydroponic Production", Urban Forestry \& Urban Greening, 2020.

[3] Helmy, M. G. Mahaidayu, A. Nursyahidn, T. A. Setyawan, and A. Hasan, "Nutrient Film Technique (NFT) Hydroponic Monitoring System Based on Wireless Sensor Network", IEEE International Conference on Communication, Networks and Satellite (Comnetsat), Semarang, Indonesia, 2017.

[4] D. Adidrana, and N. Surantha, "Hydroponic Nutrient Control System based on Internet of Things and K-Nearest Neighbors", International Conference on Computer, Control, Informatics and its Applications, Tangerang, Indonesia, 2019.

[5] J. Suhl, B. Oppedijk, D. Baganz, W. Kloas, U. Schmidt, B.V Duijn, "Oxygen Consumption in Recirculating Nutrient Film Technique in Aquaponics”, Scientia Horticulturae, 255, pp. 281-291, 2019.

[6] T. Kaewwiste, T. Yooyativong, "Electrical Conductivity and pH Adjusting System for Hydroponics by Using Linear Regression", International Conference on Electrical/Electronics, Computer, 
Telecommunications and Information Technology (ECTI-CON). Phuket, Thailand. 2017.

[7] S. Mashumah, M. Rivai, A. N. Irfansyah, "Nutrient Film Technique based Hydroponic System Using Fuzzy Logic Control", International Seminar on Intelligent Technology and Its Applications (ISITIA)". Surabaya, Indonesia. 2018.

[8] J. J. Ponce, J. U. L Castro., R. A Ramrez, I. I. S. Alcla, "Electrical Conductivity and Water Flow Control of a NFT System," International Journal Of Circuits, Systems And Signal Processing., vol 2, pp. 134141. 2013.

[9] E. O. Kyere, G. Foong, J. Palmer, J. J. Wargent, and G. C. Fletcher, "Biofilm Formation of Listeria Monocytogenes in Hydroponic and Soil Grown Lettuce Leaf Extracts on Stainless Steel Coupons", LWT - Food Science and Technologi, 126, 2020.

[10] Ibrahim. M.N.R, Solahudin. M, and Widodo. S, "Control System for Nutrient Solution of Nutrient Film Technique Using Fuzzy Logic", Telkominika, vol 4, pp. 1281-1288, 2015.

[11] Wahjuni. S, Maarik. A, and Budiardi. T, "The Fuzzy Inference System for Intelligent Water Quality Monitoring System to Optimize Eel Fish Farming", International Symposioum on Electronics and Smart Devices (ISESD), vol 1, pp. 163-167, 2016.

[12] D. Valis, K. Hasilova, M. Forbelska, and Z. Vintr, Realibility Modelling and Analysis of Water Distribution Network Based on Backpropagation Recursive Processes with Real Field Data, Measurement, 149, pp. 1-14, 2020.

[13] I. M. Sofian, A. K. Affandi, I. Iskandar, and Y. Apriani, "Monthly Rainfall Prediction Based on Artificial Neural Networks with Backpropagation and Radial Basis Function", International Journal of Advances in Intelligent Informatics, vol 4, no 2, pp. 154-166. 2018.
[14] C. Xu, D. Liu, L. Zhang, X. Chen, Y. Sui, H. Zhang, and H. Ma, "Influence of Temperature Fluctuations on the State/Phase, Ice Crystal Morphology, Cell Structure, and Quality of Celery During Frozen Storage", LWT - Food Science and Technology, 125, 2020.

[15] Embarsari. R.P, Taofik. A, Qurrohman. B.F.T. "Pertumbuhan dan Hasil Seledri (Apium graveolens L.) pada Sistem Hidroponik Sumbu dengan Jenis Sumbu dan Media Tanam Berbeda," Jurnal Agro., vol 2, pp. 41-48. 2015.

[16] M. Anastasiadi, N. Falagan, S. Rossi, L. A. Terry, “A Comprehensive Study of Factors Affecting Postharvest Disorder Development in Celery", Postharvest Biology and Technology, 172, 2021.

[17] M. Salintiro, A. V. D. Ent, A. Tognacchini, A. Tassoni, Stress Responses and Nickel and Zinc Accumulation in Different Accessions of Stellario Media (L.) Vill. In Response to Solution $\mathrm{pH}$ Variation in Hydroponic Culture. Plant Physiology and Biochemistry. 148. Pp. 133-141. 2020.

[18] B. Yep, N. V. Gale, Y. Zheng, “comparing Hydroponic and Aquaponic Rootzones on The Growth of Two Drug-type Cannabis Sativa L. Cultivars During The Flowering Stage", Industrial Crops \& Products, $157,2020$.

[19] Untung. Hidroponik Sayuran Sistem NFT (Nutrient Film Technique). Jakarta, Indonesia: Penebar Swadaya. 2000.

[20] N. Khatri, K. K. Khatri, A. Sharma, "Artificial Neural Network Modelling of Faecal Coliform Removal in an Intermittent Cycle Extended Aeration System-sequential Batch Reactor Based Wastewater Treatment Plant", Journal of Water Process Engineering, 37. 2020 . 